\title{
Knowledge management: library and information science writ large
}

\author{
Qiping Zhang and Michael E. D. Koenig
}

\section{The LIS Origin of KM}

The origin of Knowledge Management, KM, is conventionally traced to the realization on the part of the major consulting firms that the Internet, particularly intranets specific to a particular organization, were marvelously useful tools with which to share information within that organization. From that came the realization that in applying intranets for their own organization, and in the process creating lessons learned databases, expertise locators, communities of practice, and so on, they had developed tools that constituted an expertise that could be very successfully marketed to other organizations. In short, they realized that they had an important new product. An important new product of course deserves a crisp and compelling new term, a new name, a compelling new descriptor in LIS terminology. The name that arose was Knowledge Management.

\subsection{First Users of the Term "Knowledge Management"}

The first users of the term "Knowledge Management" appear to have been at consulting firms like Arthur D. Little, McKinsey and Company, and Ernst and Young (EY). The first KM event was a conference at the Four Seasons Hotel in Boston, organized by the Center for Business Strategy at Ernst and Young in the spring of 1993 (Prusak, 1999). The term KM began appearing in the management literature in the early 1990s. There were, however, articles about what we would now recognize as KM well before that. A classic such article is Don Marchand's “Information Management” (Marchand, 1985), which any observer now would call KM. The development of KM is well treated by Prusak 
(1999), Koenig (2000), Koenig and Neveroski (2008), and McInerney and Koenig (2011), the latter including a rather detailed description of the stages of KM development.

The origin of KM also owes a great deal to the attention paid to intellectual capital (IC), the recognition that the knowledge and information possessed by an organization is a very important part of its capital and assets (not just the traditional components described as capital, such as financial capital or tangible and physical assets), and that IC needs to be preserved, created, used, and measured. The development of intellectual capital can be traced back to Peter Drucker (Hibbard, 1997). The key promoters of IC were Sveiby, author of The Invisible Balance Sheet (Sveiby, 1989); Stewart, whose article in Fortune magazine, "Your Company's Most Valuable Asset: Intellectual Capital" (Stewart, 1994) was widely read and quoted; and Edvinsson who illustrated the large-scale implementation of IC at a large organization, Skandia (Edvinsson, 1994, 1997). While enthusiasm for attempting to measure IC receded dramatically, simply due to the recalcitrant and intractable nature of measuring information and knowledge (McInerney and Koenig, 2011), the focus played an important role in propelling the development of KM. As a consequence, $\mathrm{KM}$ has been described, using equestrian terminology, as a creation "by the Internet out of intellectual capital" (Koenig, 2000). But, the IC movement also served to confirm that knowledge, the domain of librarianship, is the substrate of KM.

\subsection{Different Focus of KM and LIS}

$\mathrm{KM}$ is not only logically, but also realistically, a straightforward extension of library and information science (LIS). The difference is that LIS is primarily about locating, organizing and deploying information external to the organization, while KM is primarily about the organization's own knowledge and information, as well as the organizational culture and strategy. The classic expression, in the early days of KM, illustrates the focus on the organization's own knowledge and information: "If only Texas Instruments knew what Texas Instruments knew” (Davenport and Prusak, 1998; O’Dell and Jackson, 1998). Liebowitz and Paliszkiewicz (2019) make the point that Borko's (1968) classic definition of "information science," probably not bettered to this date, is so inclusive that there is no functional part of KM that is not included within it.

KM's extension of library and information science is, however, an extension that has substantially grown in breadth, and has become much more central to management decision making. The extension is not about the functional components of KM work; rather, it is about how to set the scene for KM to 
function. Another way to make the distinction is that the fundamental difference that emerges between LIS and KM is that KM involves issues that need to be addressed at a much higher level in the organization than LIS issues historically have been treated. Perhaps the most compelling illustration of that point is that KM involves how to design the organization's very structure, and how to design and implement the organization's compensation and reward system so as to facilitate information and knowledge sharing. LIS historically never concerned itself at any really substantive level with such issues. The closest it came were some attempts at embedding LIS professionals within research teams, a topic frequently discussed and advocated in the LIS literature, but seldom implemented in practice. KM practice, however, has greatly expanded upon that idea, and in many cases takes it for granted. It is common now to assign KM members to divisions, departments, teams and projects.

\subsection{Three Stages of KM}

The essential commonality of KM and LIS was not initially realized by the KM community. As Koenig $(1992,2000)$ has pointed out, KM emerged in three clear stages. The first stage was about deploying the technology and setting up the intranets. The second stage was about appreciating the human factor aspects of $\mathrm{KM}$ - the recognition that it is pointless to set up the systems, no matter how capable and elegant, if people don't use them. The hallmark phrase for stage 2 was "communities of practice." Stage 3 was about content and content description. It's no use getting people onto the system if they can't find what they want or need. Stage 3 was the knowledge organization stage; the hallmark phrase was "content management." It was not until stage 3 , approximately in the late 1990s, that what might be called the traditional IT-driven KM community realized that what they were calling taxonomies, a term borrowed from the natural sciences, were fundamentally the same as what the LIS community had been developing for years as syndetic structures and knowledge classification schemes. The fact that this realization occurred rather late in the development of KM applications continues to obscure the fact that KM is logically an extension of LIS, and not a separate domain.

\subsection{Development of a Semantic Web}

What has recently reinforced the recognition of the overlap between the IT and the LIS components of KM is the desire to build a truly functional "semantic web." These developments are coalescing around the recognition that the structure of the semantic web at the granular level will be based on "triples": subject, predicate, and object combinations. Both the LIS and the IT communities arrived at the same conclusion simultaneously, and had the 
good sense to realize that they were attempting to create the same thing. Some developments in the semantic web community, particularly the areas of taxonomy and ontology, concerning data description and structuring (e.g., RDF, Resource Definition Framework, and SPARQ, the RDF query language) can be traced to the LIS tradition. Others (such as the web ontology language, OWL) can be traced to the Internet/IT tradition. Increasingly, new developments are simply jointly related. A good example of overlap is the two major players within this taxonomy/ontology area. One, Data Harmony (accessinn.com), descends directly from the LIS side, while the other, Synaptica (synaptica. com), clearly descends from the IT side. This area is increasingly coalescing into one community. These are the tools that KM managers increasingly need to be familiar with. They are rooted in and will be developing from and within the LIS tradition.

\subsection{Push Technology and SDI}

One KM practice that derived directly from the LIS realm is so called "push methodology"; that is, sending information out to users, rather than waiting for them to ask for it. This is a straightforward extension of selective dissemination of information (SDI). SDI developed concurrently with "machine readable databases" in the1960s. It was simply the notion that a standing query could be run whenever a batch of new update tapes arrived. (Yes, computer searches were run in batch mode against computer tapes, before online capability appeared on the scene.) When online search capability arrived, the obvious thought was to store the retrospective search as a search profile that could be run to update and add to the search when new material was added to the database. The next logical extension was to ask users to describe their topical interests, particularly research interests, and then write a profile to reflect those interests and run it periodically and routinely. Thus, SDI was born. It was a particularly compelling idea at the time before effective online capability when a retrospective literature search could require 12 hours of the company's mainframe computer (the author's personal experience at Pfizer in the early 1970s), while a weekly or fortnightly search of just the new tapes could relatively easily be shoehorned in. A historical note is that in corporate libraries ("special libraries") it was common practice, well before computers arrived, for librarians to scan newly arrived journal issues, and alert researchers and executives to relevant articles, a "manual" SDI service.

A good example of the unawareness within the IT and KM communities of KM's LIS antecedents is Marcia Bates' (2002) description of being contacted by an information broker who had been retained to resolve a friendly argument among two dot-com companies as to which company had invented push tech- 
nology. Their goal, as Bates explains, was to confirm that no third party had invented it earlier, that there was no "prior art." The companies were stunned to be informed that push technology originated in pre-DASD (direct access storage device) tape-based bibliographic databases in the LIS and documentation world in the early 1960s (Luhn, 1961).

\subsection{The Networked Information Age}

An aside, but a relevant one that makes an important point about the very early LIS basis of KM in the LIS community in the digital age, is the phenomenon of LIS professionals bemoaning the frequent popular press item about the modern networked information age. The offending article traces a bit of history and points out that the networked information age goes back well before the Internet, and typically mentions the origin of the Arpanet at MIT in the early 1970s. The librarian immediately wonders "OK, where is the follow-on paragraph about librarians and remote database searching over Tymnet and Telenet even before the Arpanet?" - that is, where the networked information age began.

\subsection{Taxonomy Boot Camp}

A telling token of KM's fundamental debt to LIS is the two-day Taxonomy Boot Camp provided at the annual KMWorld Conference. Commencing in 2006, it has now been running for fifteen years. It is aimed not at experienced KM practitioners, but at those entering the KM domain. A close look at the syllabus for Taxonomy Boot Camp reveals that it is basically composed of the concepts of LIS 101, classification and cataloging. There is a new crop of KM neophytes every now and then. A major contribution of LIS to KM will continue to be in the area of education and training. As pointed out, $\mathrm{KM}$ is a continuation and elaboration of LIS. The chain of continuity is that of organizing information and information resources in a fashion that makes them locatable and retrievable. LIS has historically referred to this area as classification and cataloging, while KM has adopted the term taxonomy for essentially the same thing. The salient point is that the Taxonomy Boot Camp is the closest equivalent that the field of KM has to a Knowledge Management Boot Camp.

\section{Training for $\mathrm{KM}$}

There is a marked need for training in the area of KM practice. KM operations are expanding and new recruits are needed. Most practitioners enter the KM 
realm not from academic programs focusing on KM, or even featuring KM, but rather they transfer over and into KM from line operational jobs within their organization, not from outside the organization. The reason for that is precisely the lack of potential job applicants with KM training. The ideal candidate would be someone with KM training as part of their academic qualifications and enough experience within the organization to have a good sense of its context. There are very few such people. Senior KM people, however, are, not uncommonly, brought in from outside, based on their experience in other organizations. The rationale for this state of affairs is that for bench level or front line KM positions, supporting a particular division or project, it is probably most important that the candidate know a great deal about the context of that division or project, than it is that they have KM experience or training. The assumption is that they can pick up KM techniques or skills on the job. On the other hand, for senior KM positions overseeing a broad range of operations, the assumption is usually that the qualifications needed are successful KM management experience and particularly good interpersonal and communication skills.

For those KM newbies moving into or transferring over to front line or bench level positions, the obvious question is whether on the job learning is sufficient or adequate. Would it not be preferable to have some sort of crash course in $\mathrm{KM}$ available to them, a course that could bring them quickly up to speed in KM techniques and tactics? How are those programs to be organized and who runs them? For such persons, typically already employed, the programs need to be easily accessible and relatively brief. Given now the world's COVID-19 constraints, the obvious choice would seem to be online delivery. The question is who is best suited to organize and deliver such programs? Who is in a position to provide such training? As Cervone (2017) makes clear in his study of $\mathrm{KM}$ curricula, KM education is scattered, and inconstant; KM programs have come and gone and been restructured with surprising frequency. It is clear that no consistent pattern of KM education has emerged, nor do developments to date (KM has been around long enough to reasonably expect that a pattern should have appeared) suggest that a clear pattern is likely to emerge.

The obvious candidates, then, for KM training and education are:

- LIS programs

- Business schools

- Professional KM organizations and associations

- Independent for-profit KM organizations. 


\subsection{LIS Programs}

The two most obvious providers for KM education and training at present are LIS programs and KM organizations; LIS programs because they have always seen data and information organization as central to their role and have substantial on-board expertise. KM organizations are also a reasonable candidate because presumably they are all about KM.

However, the LIS academic community appears to be making only slow and modest efforts to move in this direction. A recent article reporting on the "Diffusion of KM Education in LIS Schools" (Katuščáková and Jasečková, 2019) illuminates that conclusion. Their study, very international in coverage, found that only one-third of LIS programs had incorporated KM in an aggressive way. Among those schools with a focus on information science as well as LIS, the proportion was close to half. This is still somewhat surprising given that there is an extensive literature calling for (Koenig, 2005) and reporting about the incorporation of KM into LIS programs (Hazari et al., 2009; Roknuzzaman and Katsuhiro, 2010).

\subsection{Business Schools}

Business Schools (B-Schools), have not aggressively incorporated KM training and education into their curriculums. They have so far been even more passive than LIS programs. The literature about KM in business school curricula is conspicuous by its relative absence, in marked contrast to the LIS literature. Their literature is related to very specific programs, rather than to the field at large (Olszak and Ziemba, 2010). However, as business schools adapt to the consequences of COVID-19, it is quite likely that they will be placing more emphasis upon the online delivery of courses, and upon the creation of programs that can be directed to those already employed and those for whom on-campus programs are simply not practical, including those who already have an MBA. In that context, KM programs would seem to be an obvious opportunity for B-Schools attempting to maintain or recover, or even expand enrollment and revenue. The authors expect that there will be motion on this front.

\subsection{Professional KM Organizations and Associations}

Professional KM Associations, and there are, or have been, a number of them, are indeed making some efforts. Overall activity among these players seems to be receding a bit. 


\subsubsection{KMI (kminstitute.org)}

The Knowledge Management Institute has an active program of conferences and workshops, and a successful (10,000 graduates in 20 years) program of certification.

\subsubsection{NetIKX (netikx.org)}

The Network for Information and Knowledge Exchange was founded in 2006, but descends from the 1990s enthusiasm for information resource management (IRM), and the proselytization of Woody Horton. The NetIKX group was created in 1992. Its role remains that of hosting numerous seminars, primarily in London, most of which focus on KM. It also has a relationship with Taxonomy Boot Camp.

\subsubsection{KMPro (KMPro.org)}

The Knowledge Management Professional Society, founded in 2001, was, for some years, probably the most active professional society, but after internal political difficulties, it has become moribund and its website is no longer active.

\subsubsection{IAKM (http://iakm.weebly.com/)}

The International Association for Knowledge Management organizes conferences, IFKAD (International Forum on Knowledge Asset Dynamics) and ICKMAP (International Conference on Knowledge Application and Practice), which of course include sessions relating to KM training and education. IAKM, however, plays little role in education and training outside its conference venues.

\subsubsection{KMCI (kmci.org)}

The Knowledge Management Consortium International, which originated in 1997, was an attempt to link KM with the then new enthusiasm for complexity theory. KMCI discontinued membership in 2002. Its website still describes an extensive array of KM certifications, but the phone number listed on the website is disconnected.

\subsubsection{AOK \& KMedu Hub (kmeducationhub.de)}

The Association of Knowledge Work is no longer active per se. It was discontinued in 2010. The organization, however, maintains KMedu Hub (kmeduca- 
tionhub.de) that is an extensive list, quite international, of those organizations which provide KM training. Indeed, there is also a list of other organizations which provide similar KM education and training information, in many cases at a more specific national or regional level.

A striking phenomenon is the high morbidity rate for $\mathrm{KM}$ associations. Another subtle phenomenon that can be noticed by any long-term KM observer is the very low level of overlap between those persons active with any one of these professional groups and those active with any other. A bibliometric display based on professional association membership and social media would reveal a very dispersed and scattered KM field.

\subsection{Broader Scale Professional Organizations}

A number of broader scale professional organizations, typically in the library domain, venture into the KM field and offer some KM training and education.

\subsubsection{IFLA (https://ifla.org/)}

The International Federation of Library Associations has a long history of interest in KM. Its general conferences frequently have sessions to bring librarians up to speed about KM. Its first session focusing on KM was in 1998. In 2003, IFLA created a section on KM, and in 2005, the all-hands opening session at the annual conference was devoted to KM. However, IFLA's audience is librarians who by default are to a degree already in the KM fold. It is not expanding the field.

\subsubsection{SLA (https://www.sla.org/)}

The Special Libraries Association has a carefully worded and well thought out statement of "Competencies for Information Professionals," a document that could almost equally well be a statement of core competencies for KM. Like IFLA, however, its audience is librarians who are usually already KM-aware and functionally already in the field.

\subsubsection{ASIS\&T (https://www.asist.org/)}

The Association for Information Science and Technology has a special interest group (SIG), devoted to KM. The SIG's archives go back to 2002, but sessions on KM in ASIS\&T's annual conferences go back well before that. 


\subsubsection{ISKO (https://www.isko.org/)}

Founded in 1989, the International Society for Knowledge Organization is also interested in the KM field. ISKO has become the parent to the European Knowledge Acquisition Workshop (EKAW) which commenced in 1987. Rather surprisingly, however, the phrase "Knowledge Management" is nowhere to be found in their carefully compiled ISKO Encyclopedia of Knowledge Organization. Despite that, ISKO is an affiliated sponsor of the Washington and London Taxonomy Boot Camps mentioned above.

\subsubsection{APQC (https://www.apqc.org/)}

The American Productivity and Quality Center was founded in 1977, before KM was a buzzword. It was founded to make American industry more competitive, particularly with Japanese industry. APQC's primary focus was on publicizing, incorporating, and learning from Japanese techniques, particularly the concepts of benchmarking and best practices, and undertaking research about how to improve productivity. Very rapidly, however, APQC came to see KM and the promotion of KM as central to its mission. Consequently, the subject of much of APQC's well-attended conferences, and the focus of much of its research and the subject of many of its publications is KM. In fact, APQC's tag line is now "APQC, the world's foremost authority in benchmarking, best practices, process and performance improvement, and knowledge management." Consequently, APQC runs workshops and webinars specifically about $\mathrm{KM}$ issues. APQC is a major resource for the field.

\subsection{Independent For-Profit KM Organizations}

Some independent for-profit organizations have entered the field - they sense opportunity and have established an expertise.

\subsubsection{Information Today (informatintodayinc.com)}

A major player in this area is Information Today, organizers of the annual KMWorld Conference, whose origins come from the library database world. Information Today is a long-time player in the area of trade shows and conferences centered on the library and information domain. Well before there was a Google or an Amazon, they were the organizers of the National Online Conference (New York) and co-sponsors of the International Online Conference (London). It is sobering to realize that barely more than 20 years ago it was quite reasonable and appropriate to label a combined conference and trade show devoted almost entirely to library systems and services and to 
bibliographic databases, the "National Online" meeting. It was still a world in which Google and Amazon and Facebook did not yet exist, and in which the most active group of online system users were librarians. Rather seamlessly, the National Online Conference morphed into the KMWorld Conference. The conference, as much a trade show as a conference, features how-to and lessons learned sessions, many aimed at newbies to the field. It has become, at least in North America, the major route of KM education for those entering the field. A major component of the KMWorld Conference, as mentioned above, is the Taxonomy Boot Camp, which has become successful enough to be offered as a stand-alone event, and which is given in London as well. One can expect this model to continue successfully, but to transition to a more online-enabled delivery model.

\subsection{Future Directions for Training and Education}

The activity related to KM training and education seems to be primarily in the hands of LIS programs and other organizations such as the Knowledge Management Institute (KMI) and Information Today (KMWorld). What is clear is that KM training and education very much descended from the LIS/ database domains, either LIS academic programs or for profit organizations targeting the LIS community.

\section{Future Directions for LIS-related KM}

There are many future directions for LIS to pursue related to KM because of the potential benefits of KM for the LIS profession (Liebowitz and Paliszkiewicz, 2019). In the following, two such directions are identified and will be discussed: the semantic web, and concept identification and retrieval.

\subsection{The Semantic Web}

The semantic web (also called Web 3.0) deals with annotating information based on underlying common use of knowledge representation so that such semantics can be reused by computer systems/artificial intelligence or machine learning for users to find, organize, access and maintain the information they seek (Davies et al., 2007). While the World Wide Web uses HTML, a markup language to describe format, XML provides a markup language for semantics (Warren, 2006). In addition, the underlying principles and technologies of the semantic web are built based on LIS areas of taxonomy and ontology. The new development of the semantic web provides opportunities to improve 
knowledge management. By integrating human involvement in information/ knowledge management activities and integrating knowledge creation and use, it provides a flexible reference mechanism to knowledge objects and knowledge contributors.

Semantic technologies have been widely researched and applied in many areas. For the area of data quality management, some have focused on the development of the semantic data quality management (SDQM) framework (Fürber, 2015; Fürber and Hepp, 2013). Others use ontologies to develop new semantic applications for different sectors such as life sciences, healthcare, government, or technology-intensive sectors (Sheth and Stephens, 2007).

As semantic-based knowledge management becomes a critical enabler for improving organizational performance, more organizations will use the power of semantics in their business strategies (Eine et al., 2017). Compliance issues such as financial compliance (particularly money laundering, anti-terrorism), environmental concerns and non-discrimination are increasingly important. Consider money laundering and the thousands of corporations chartered in the Cayman Islands, many if not most with overlapping ownership, in many cases deliberately created to foster obscurity. Who ultimately is the beneficiary of any particular financial transaction? This is an issue designed to be elucidated by the concepts of the semantic web. Another area of semantic web application is ontology-based big data management (Eine et al., 2017; Fensel, 2002). No matter whether a large enterprise or a small or middle-sized organization, an ontology-based big data management system will acquire, maintain and access weakly structured data sources in order to reduce the complexity of business data and processes. Finally, semantic wikis are another example of application of semantic technology (Schaffert, 2006). By annotating existing wiki links based on their content, semantic technologies (RDF, OWL, Topic Map, or Conceptual Graphs) make the inherent structure of a wiki accessible to machines (agents, services) beyond mere navigation. The semantic wiki development will provide support not only to collaborative knowledge engineering through linguistic processing techniques, identification of similar concepts, but also to collaborative learning through automated structure analysis and guided questions based on underlying ontological knowledge.

While the semantic web has been applied in the area of LIS/KM applications, we expect to see substantial development work in this area. 


\subsection{Concept Identification and Retrieval}

Information retrieval systems traditionally rely on textual keywords to index documents and queries. Documents are retrieved based on the number of keywords shared with the query. Such lexical-focused retrieval leads to inaccurate and incomplete results when different keywords are used to describe the same concept in the documents and in the queries. In addition, the relationship between these related keywords may be semantic rather than syntactic, and capturing it thus requires access to comprehensive human knowledge.

Concept-based retrieval approaches attempt to overcome this problem by relying on concepts rather than on keywords to indexing and retrieval. The key is to retrieve documents that are semantically relevant to a given user query. To successfully retrieve relevant information, indexing should be achieved using the concepts of the document that an author intends to highlight. Thus, concept-based retrieval is achieved by using manually built thesauri, by relying on term co-occurrence data, or by extracting latent word relationships and concepts from a corpus.

Different concept identification indexing methods have been developed for information retrieval. First, a fuzzy ranking model calculates the relevance ranking based on the user preference. It is indexed by concept identification (Kang et al., 2005). Second, lexical databases such as WordNet and WordNet domains are used for concept identification. The identified concept is then weighted based on the definition of concept centrality. The resulting semantic-based retrieval approach is shown to be more effective than traditional IR approaches (Boubekeur and Azzoug, 2013; Boubekeu et al., 2010). Third, several techniques address the issue of textual variation in the documents and queries in IR systems (Aronson, 1996; Riloff, 1995). By normalizing both document text and queries, text words are replaced with concepts discovered by a program mapping texts to the concepts in the meta thesaurus. Actual retrieval is accomplished by processing the normalized text using a traditional statistical IR system.

Concept identification indexing approaches have been used for information retrieval in different domains. Zheng and $\mathrm{Yu}$ (2015) developed a system for medical information retrieval. The medical terms in electronic health records (EHRs) are often hard for patients to understand. By exploring topic model and key concept identification methods to construct queries from the EHR notes, they provided tailored online consumer-oriented health education materials. Lin et. al. (2012) implemented a concept-based IR system for engineering domain-specific technical documents. While technical documents 
often have complicated structures, their partitioning approach separates each document into several passages, and treats each passage as an independent document. Passages are generated according to domain knowledge, which is represented by base domain ontology.

Concept-based video retrieval is a promising area. Traditional video retrieval is based on the textual description of the video, which is manually indexed by library experts using controlled vocabularies. While social tagging by general users is easy and fast, their labels are ambiguous, limited, and overly personalized. Furthermore, unlabeled video segments remain notoriously difficult to find. The emergence of the new field of content-based image retrieval from the 1990s facilitates searching in video at a segment-level by means of large sets of automatically detected (visual) concepts. Machine-driven labeling derives meaningful descriptors from video data. Central to the issue is the notion of a semantic concept: an objective linguistic description of an observable video entity. The challenge is the semantic gap, the lack of correspondence between the low-level features that machines extract from video content and the high-level conceptual interpretation of video segments by an interacting user (Smeulders et al., 2000). Snoek and Worring (2008), after reviewing over 300 references, pointed out that concept-based video retrieval can be achieved by empowering a video search engine with its automated detection, selection under uncertainty, and interactive usage. Its success is due to the interdisciplinary influences from information retrieval, computer vision, machine learning, and human-computer interaction.

There are a variety of concept-based IR software tools (Haav and Lubi, 2001). Concept-based IR embed "intelligence" to search tools to manage effectively search, retrieval, filtering, and presenting relevant information. Rahman and Roy (2017) developed two IR techniques TextRank and POSRank to determine a term's importance based on not only its co-occurrences with other important terms but also its syntactic relationships with them. It leads to identification of better quality search terms than baseline terms. Poshyvanyk et al. (2013) proposed a concept location tool using formal concept analysis and latent semantic indexing, an advanced IR approach. By mapping textual descriptions of software features or bug reports to relevant parts of the source code, it presented a ranked list of source code elements. For the given ranked list, the approach selects the most relevant attributes from the best ranked documents, clusters the results, and presents them as a concept lattice. This approach was shown to be effective in organizing different concepts and their relationships present in the subset of the search results. Egozi et al. (2011) provided a concept-based information retrieval system using explicit semantic analysis (ESA). The system extracted new text features automatically from massive human knowl- 
edge repositories, thus augmenting keyword-based text representation with concept-based features. The high-quality feature selection becomes crucial in this setting to make the retrieval more focused. In summary, the research on concept identification retrieval will continue to grow in the future.

\section{References}

Aronson, A. R. (1996). The effect of textual variation on concept based information retrieval. In Proceedings of the AMIA Annual Fall Symposium (p. 373). American Medical Informatics Association.

Bates, M. (2002). After the dot-bomb: getting web information retrieval right this time. First Monday 7(7), July. https://firstmonday.org/ojs/index.php/fm/article/view/971/ 892.

Borko, H. (1968). Information Science, What is it? American Documentation 19(1), $3-5$.

Boubekeur, F. \& Azzoug, W. (2013). Concept-based indexing in text information retrieval. arXiv preprint arXiv. DOI: 10.5121/ijcsit.2013.5110.

Boubekeur, F., Boughanem, M., Tamine, L. \& Daoud, M. (2010, October). Using WordNet for concept-based document indexing in information retrieval. In Fourth International Conference on Semantic Processing (SEMAPRO), Florence, Italy.

Cervone, F. (2017). What does the evolution of curriculum in knowledge management programs tell us about the future of the field?, VINE Journal of Information and Knowledge Management Systems 47(4): 454-66.

Davenport, T. \& Prusak, L. (1998). Working Knowledge: How Organizations Manage What They Know. Boston, MA: Harvard Business School Press.

Davies, J., Lytras, M. \& Sheth, A. P. (2007). Guest editors' introduction: semantic-web-based knowledge management. IEEE Internet Computing 11(5), $14-16$.

Edvinsson, L. (1994). Visualizing Intellectual Capital at Skandia, Skandia's 1997 Annual Report. Stockholm: Skandia AFS.

Edvinsson, L. (1997). Developing intellectual capital at Skandia. Long Range Planning 30(3), 366-73.

Egozi, O., Markovitch, S. \& Gabrilovich, E. (2011). Concept-based information retrieval using explicit semantic analysis. ACM Transactions on Information Systems (TOIS) 29(2), 1-34.

Eine, B., Jurisch, M. \& Quint, W. (2017). Ontology-based big data management. Systems 5(3), 45.

Fensel, D. (2002). Ontology-based knowledge management. Computer 35(11), 56-9.

Fürber, C. (2015). Data Quality Management with Semantic Technologies. Dordrecht: Springer.

Fürber, C. \& Hepp, M. (2013). Using semantic web technologies for data quality management. In Handbook of Data Quality, ed. Shazia Sadiq (pp. 141-61). Berlin/ Heidelberg: Springer.

Haav, H. M. \& Lubi, T. L. (2001). A survey of concept-based information retrieval tools on the web. In Proceedings of the 5th East-European Conference ADBIS (Vol. 2, pp. 29-41). 
Hazari, A., Martin, B. \& Sarrafzadeh, M. (2009). Integration of Knowledge Management with the Library and Information Science Curriculum: some professional perspectives. Journal of Education for Library and Information Science 50(3), 152-63.

Hibbard, J. (1997). Knowing what we know. Information Week, 653 (October 20), 46-64.

Kang, B. Y., Kim, D. W. \& Kim, H. J. (2005). Fuzzy information retrieval indexed by concept identification. In International Conference on Text, Speech and Dialogue (pp. 179-86). Berlin/Heidelberg: Springer.

Katušč́ková, M. \& Jasečková, G. (2019. Diffusion of KM education in LIS schools, Journal of Education for Library and Information Science 60(1), 83-100.

Koenig, M. E. D. (1992). Entering Stage III - the convergence of the stage hypotheses. Journal of the American Society for Information Science 43(3), 204-7.

Koenig, M. E. D. (2000). The evolution of knowledge management. In T. K. Srikantaiah and M. E. D. Koenig, Knowledge Management for the Information Professional (pp. 23-36). Medford, NJ: Information Today for the American Society for Information Science.

Koenig, M. E. D. (2005). KM moves beyond the organization: the opportunity for librarians. Information Services and Use 25(2), 87-93.

Koenig, M. E. D. and Neveroski, K. (2008). The origins and development of knowledge management. Journal of Information and Knowledge Management 7(4), 243-54.

Liebowitz, J. \& Paliszkiewicz, J. (2019). The next generation of knowledge management: implications for LIS educators and professionals. Online Journal of Applied Knowledge Management 7(2), 16-28.

Lin, H. T., Chi, N. W. \& Hsieh, S. H. (2012). A concept-based information retrieval approach for engineering domain-specific technical documents. Advanced Engineering Informatics 26(2), 349-60.

Luhn, H. P. (1961). Selective dissemination of new scientific information with the aid of electronic processing equipment. American Documentation 12(3), 131-8.

Marchand, D. (1985). Information management: strategies and tools in transition. Information Management Review 1(1), 27-37.

McInerney, C. M. \& Koenig, M. E. D. (2011). Knowledge Management (KM) Processes in Organizations. San Rafael, CA: Morgan and Claypool.

O’Dell, C. \& Jackson, C. (1998). If only we knew what we know: identification and transfer of internal best practices. California Management Review 40(3), 305-8.

Olszak, C. M. \& Ziemba, E. (2010). Knowledge management curriculum development: linking with real business needs. Issues in Informing Science and Information Technology 7(1), 235-48.

Poshyvanyk, D., Gethers, M., \& Marcus, A. (2013). Concept location using formal concept analysis and information retrieval. ACM Transactions on Software Engineering and Methodology (TOSEM) 21(4), 1-34.

Prusak, L. (1999). Where did knowledge management come from? Knowledge Directions 1(1), 90-96.

Rahman, M. M. \& Roy, C. K. (2017, February). STRICT: Information retrieval based search term identification for concept location. In 2017 IEEE 24th International Conference on Software Analysis, Evolution and Reengineering (SANER) (pp. 79-90). IEEE.

Riloff, E. (1995, July). Little words can make a big difference for text classification. In Proceedings of the 18th Annual International ACM SIGIR Conference on Research and Development in Information Retrieval (pp. 130-36). 
Roknuzzaman, M. \& Katsuhiro, U. (2010). KM education at LIS schools: an analysis of KM masters programs. Journal of Education for Library and Information Science 51(4), 267-80.

Schaffert, S. (2006, June). IkeWiki: a semantic wiki for collaborative knowledge management. In 15th IEEE International Workshops on Enabling Technologies: Infrastructure for Collaborative Enterprises (WETICE'06) (pp. 388-96). IEEE.

Sheth, A. P. \& Stephens, S. (2007). Semantic web: technologies and applications for the real-world. World Wide Web Conf. tutorial, 2007. http://www2007.org/tutorial -T11.php and http://knoesis.wright.edu/library/presentations/WWW2007-Sheth -Stephens-Tutorial-Final.ppt.

Smeulders, A. W., Worring, M., Santini, S., Gupta, A. \& Jain, R. (2000). Content-based image retrieval at the end of the early years. IEEE Transactions on Pattern Analysis and Machine Intelligence 22(12), 1349-80.

Snoek, C. G. \& Worring, M. (2008). Concept-based video retrieval. Foundations and Trends in Information Retrieval 2(4), 215-322.

Stewart, T. (1994). Your company's most valuable asset: intellectual capital. Fortune, 130 (Oct. 3), 68-74.

Sveiby, K. (1989). The Invisible Balance Sheet. Stockholm: Affärsvärlden Förlag.

Warren, P. (2006). Knowledge management and the semantic web: from scenario to technology. IEEE Intelligent Systems 21(1), 53-9.

Zheng, J. \& Yu, H. (2015, September). Key concept identification for medical information retrieval. In Proceedings of the 2015 Conference on Empirical Methods in Natural Language Processing (pp. 579-84). 
Qiping Zhang and Michael E. D. Koenig - 9781800370623 